\title{
Vivir con la televisión. 30 años de análisis de cultivo
}

\author{
Hugo García Álvarez*
}

Recibido: 28 de agosto de 2008

Aprobado: 10 de octubre de 2008

\section{Resumen}

Este trabajo tiene como objetivo discutir y explorar la importancia de los estudios empíricos a propósito de los efectos de la televisión. En particular se centra en un una recostrucción del proyecto Indicadores culturales, lidereado por George Gerbner. Se analizan las principales aportaciones y modificaciones teóricas y metodológicas que ha experimentado el enfoque a lo largo de sus más de 30 años de existencia.

El análisis del cultivo ha puesto en evidencia la importante participación de la televisión en la construcción de la realidad social de los televidentes en cuanto a sus estimados sobre violencia y la presencia de ciertos grupos en la sociedad y la evaluación que de ellos hacen los televidentes asiduos, así como los modelos que explican este fenómeno.

Se discuten también algunos trabajos que desde este enfoque se han realizado en otros países y se analizan las posibilidades de implementación en México, donde el sistema de la televisión articula programación nacional con programación de origen estadounidense.

\section{Palabras clave}

análisis del cultivo, consumo de televisión, efectos, investigación en comunicación.

* Magíster y candidato a doctor en el programa de Estudios Humanísticos, Comunicación y Estudios Culturales por el ITESM, campus Monterrey. Investigador asociado en el Centro de Investigación en Comunicación del ITESM*. Correo electrónico hugogarciaa@gmail.com 


\section{Living with TV: 30 years of analysis}

\section{Abstract}

The purpose of this paper is to discuss and explore the importance of empirical studies about television effects. In particular it focuses on a reconstruction of the Cultural Indicators Project led by George Gerbner; his main contributions as well as his theoretical and methodological modifications, which the approach has gone through during 30 years, are analyzed.

This analysis has shown the important participation of television in the construction of TV viewers' social reality in relation to their concepts on violence and presence of certain groups in society, as well as the evaluation TV viewers make of them, and models explaining this phenomenon.

Some researches conducted under this approach in other countries are discussed; possibilities for their implementation in Mexico, where TV system articulates national programming with the USA programming, are analyzed.

\section{Key words}

Analysis, TV viewing, effects, research in communication. 


\section{ANTECEDENTES}

La televisión ocupa un lugar en la mayoría de los hogares, y en algunos ocupa incluso más que un espacio.

La televisión tiene una importante presencia en la vida cotidiana en México. Más del 80 por ciento de personas reportan verla a diario (Séptima entrega de consumo cultural, 2001). Mientras que en el ámbito nacional el 85.6 por ciento de los hogares cuenta con televisión, en Nuevo León asciende al 95.4 por ciento (Boletín de Política Informática No. 4, 2002); en cada casa, en el país, la televisión permanece encendida siete horas y media durante el día (TV Azteca, 1999). Hay, al menos, 97 millones de personas conectadas a la televisión (Jara Elías, 1997).

Hay hogares en los que la televisión casi cumple una jornada de ocho horas y acompaña hasta cierto grado cada una de nuestras actividades exponiéndonos a ese sistema de mensajes que parece tener un papel en la aculturación y socialización, es tableciendo lecciones acerca de qué existe, qué es importante y qué es correcto, a través de la repetición y el consumo ritual (Morgan y Shanahan, 1997).

La televisión no requiere competencia alguna; los periódicos, los libros, las revistas requieren del lector que sepa leer; exponerse a la televisión no tiene ningún prerrequisito, la señal está en el aire al alcance de quienes puedan comprarse un aparato receptor, que aún siendo más caro que un libro, por el ejemplo de los huicholes, pareciera que el gasto no es necesariamen- te un impedimento: habían adquirido aparatos de televisión antes de tener energía eléctrica para encenderlos. Parece que el único prerrequisito es saber prenderla, y el control remoto ha simplificado incluso eso.

La televisión se ha integrado a nuestras vidas de muy distintas maneras. Al margen de las diferencias que pueda haber entre ellos, podemos decir que en sentido estricto una mujer huichola, un regiomontano y un niño yucateco tienen en común la televisión; si prenden la televisión en el mismo canal, a la misma hora estarán viendo exactamente lo mismo. La extensión de la comunidad expuesta a los mismos mensajes se amplía con las señales satelitales. La televisión trasciende barreras geográficas y culturales y se ha convertido en fuente de información y socialización común para poblaciones heterogéneas (Gerbner, Gross, Morgan y Signorielli, 1996).

Por eso mismo la televisión no ha sido inmune a las críticas: éstas se han enfocado principalmente en los contenidos violentos de muchos de sus programas relacionados con la presentación de conductas antisociales, especialmente sobre la violencia en el medio (Signorielli, Gerbner y Morgan 1995). Muchas críticas sostienen que los programas tienen efectos negativos en los televidentes. Por ejemplo, cuando era subsecretario de gobernación, Dionisio Pérez Jácome, expresó:

Simplemente nuestra preocupación es en función de ese segmento muy importante de la población mexicana, que son los niños, quienes pasan muchas horas sentados frente a la televisión y que, des- 
afortunadamente, en algunos casos, en horarios que son habituales para su presencia ante el televisor, puedan recibir este tipo de mensajes para los que todavía no están preparados (Román, 2000).

Este tipo de comentarios pareciera evidenciar que los televidentes no tienen la madurez necesaria para procesar los contenidos de la programación televisiva y pueden ser víctimas de influencias negativas que afecten sus actitudes y conductas.

Sin embargo, críticas de este tipo en contra de la televisión no tienen un argumento sustentado en datos. Presentan argumentos de efectos como la desvalorización, desintegración familiar y otros efectos similares que son muy difíciles de medir o atribuir a una sola fuente, como un género de televisión. Algunos otros sí aportan en sus comentarios descripciones de efectos específicos que podrían ocurrir a los televidentes, por ejemplo: «Los medios, sobre todo la televisión, esbozan un cuadro distorsionado de la situación individual, y modifican las coordenadas del imaginario social, también en lo que hace a los temores» (Fazio, 2004).

Curiosamente este autor, en ese mismo artículo, hace referencia a otros autores, cita otros trabajos, pero al llegar a esta particular aseveración no ofrece ninguna referencia. Pareciera que es de sentido común achacarle a la televisión ese tipo de influencias.

El propósito de este trabajo, en principio, es señalar la importancia de los enfoques empíricos sobre el papel de la televisión en nuestra vida diaria desde un enfoque que al menos en Estados Unidos ha estado vigente por más de 30 años: el análisis del cultivo.

A través de análisis del cultivo se ha encontrado que efectivamente los contenidos de la televisión estadounidense tienen un alto contenido de violencia, que los hombres blancos dominan el mundo de la televisión propiciando un desbalance de poder ya que los demás grupos de la población, las mujeres, los niños, las minorías, están subrepresentados y que estos contenidos influyen en la percepción de los televidentes al grado de generar una sensación de desconfianza y alienación frente al mundo en ellos (Gerbner, 1997).

En México, Estados Unidos es la fuente principal de la importación de programas: ocupa un 30 por ciento de la oferta televisiva nacional (Lozano y Huerta, 2001). Estos datos abren la posibilidad de que algo similar a lo que se ha encontrado en Estados Unidos con el análisis del cultivo también suceda en México.

La televisión pudiera influir en las percepciones sobre el mundo de los televidentes en cuestiones como la seguridad y la equidad de género a través de mensajes que justifiquen el uso de la violencia y respalden posiciones sexistas y excluyentes.

\section{ACERCARSE A LA TELEVISIÓN}

Con el objetivo de alejar la discusión sobre la televisión y sus efectos de los juicios del sentido común, han surgido diver- 
sos enfoques teóricos. Uno de los que durante más tiempo ha estado vigente, y que sí ofrece evidencia empírica, curiosamente en la misma línea que la aseveración de Fazio (2004), es el proyecto Indicadores culturales que inicia actividades en los Estados Unidos en 1967 con un estudio sobre las causas y la prevención de la violencia, concentrándose especialmente en la naturaleza y funciones de la violencia televisiva ${ }^{\text {. }}$.

Indicadores culturales nace en el marco de un debate estadounidense sobre la cantidad de violencia en la televisión (Signorielli, Gerbner y Morgan, 1995), como una alternativa de respuesta a la necesidad de determinar la influencia de la televisión con un enfoque distinto al de las influencias directas del tipo «aguja hipodérmica»².

Indicadores culturales, como proyecto, originalmente descompone el fenómeno televisivo en tres partes: el productor, el mensaje y el receptor. Y casi desde el comienzo se concentra en la violencia como eje de las investigaciones.

En este enfoque se le concede a la televisión un importante papel en la socialización de los individuos, dada su presencia en la mayoría de los hogares, convirtiéndose en la base común de una comunidad nacional conformada frente a la televisión en su doble función de informar y entretener. La te levisión es un arma cultural, es una agencia del establishment; para estabilizar y extender patrones sociales que le son afines, su principal función es la aculturación.

Según Gerbner y Gross (1976), la televisión cumple un rol equivalente al de las religiones: es la nueva manera de explicar el mundo a través de la realidad que construye. En sus programas presenta un cuadro coherente de lo que existe, qué se relaciona con qué y qué es importante; el mundo de la televisión no es el mundo real, es una extensión de las imágenes estandarizadas que nos han enseñado desde la infancia (Gerbner y Gross, 1976, p. 179) como modelos estables de comportamientos socialmente aceptables.

En este sentido, la violencia explícita o latente en la televisión será un indicador de las relaciones de poder que a la televisión le interesa transmitir y mantener, porque durante su representación estarán manifiestas ciertas normas y relaciones sociales, quiénes son los ganadores, quiénes los perdedores y cuáles son los riesgos de transgredir las reglas.

Lo crucial para Indicadores culturales no son los cambios que tal o cual mensaje provoca en el comportamiento de los individuos, sino qué tipo de conciencia común a todos los televidentes puede cultivar el sistema completo, cómo se relaciona la realidad simbólica de la televisión con la realidad simbólica del televidente; al margen de las diferencias que pueda haber entre los individuos, no se trata de las preferencias individuales sino de los mensajes a los que ningún televidente se puede abstraer (Gerbner, Morgan, y Signorielli, 1986).

Para acercarse a ese mundo simbólico, Indicadores culturales propone tres líneas de estudio:

a) Análisis de la política institucional, que se concentra en las empresas y los procesos de producción de los contenidos televisivos (base política y económica de la toma de decisiones de los medios). 
b) Una segunda línea se encarga del mensaje mismo, de los programas de televisión que son transmitidos. Esta línea recibe el nombre de análisis del sistema de mensajes y se lleva a cabo a través de un minucioso análisis de contenido de los programas de televisión, especialmente de los programas de ficción, para establecer la estructura y composición del mundo simbólico; c) y por último, la tercera línea, el análisis del cultivo, es la aproximación al receptor y su relación con el mundo de vida que se manifiesta en la televisión (Gerbner, 1997). Este acercamento se hace, esencialmente, a través de encuestas que tratan de medir la relación que se establece entre el televidente, la cantidad de programación televisiva a que se expone y el mundo de la televisión.

En función de sus objetivos, este trabajo se concentrará sólo en la relación entre el sistema de mensajes y el cultivo del mensaje de la televisión en los televidentes.

\section{AÑOS DE CULTIVO}

\section{El mundo de la televisión}

El análisis de contenido es la herramienta tradicional para caracterizar el mundo de la televisión. Desde 1967 el proyecto Indicadores culturales realiza muestreos anuales de una semana de duración de la programación de ficción de las cadenas estadounidenses «con el objeto de delinear con precisión las características seleccionadas y las tendencias que el mundo de la televisión presenta a sus espectadores» (Gerbner et al., 1996).
Hace treinta años, en la programación televisiva norteamericana, tres cuartos de los personajes principales eran hombres blancos de clase media y alta. Las mujeres representaban un cuarto de la población total, dos de cada tres personajes femeninos estaban casados o esperaban casarse. Los niños y los viejos representaban menos del 15 por ciento de la población televisiva. Ocho de cada diez programas contenían violencia, 9 de cada diez en la barra infantil, entre 6 y 7 de los personajes principales estuvieron involucrados en actos de violencia (Gerbner, 1976).

En 1999 la situación había cambiado, pero poco. Las mujeres representaban el 40 por ciento de la población televisiva, los ancianos y los niños seguían subrepresentados, los personajes blancos eran el 82.9 por ciento, mientras que en la realidad representaban un 69.1 por ciento de la población estadounidense (Harwood y Anderson 2002); en un análisis de contenido de la programación de 1997, Diefenbach y West (2001) encontraron que mientras la tasa de homicidios en los Estados Unidos era de 9.4 por cada 100,000 habitantes, en el mundo de la televisión ésta era de 932 por cada 100, 000.

\section{Aculturación, mundos en contacto}

Desde sus inicios los estudios basados en el enfoque del cultivo han buscado evidencias para sus postulados en la relación de la cantidad de televisión que ven los televidentes, los datos de sus análisis de contenido y los datos comparables del mundo real. 
La manera de medir la exposición ha cambiado en los estudios de cultivo. En un principio se pedía al entrevistado que dijera simplemente si veía mucha o poca televisión (Tan, Li y Simpson, 1986) para crear una variable nominal. Una adecuación posterior establece que la distinción entre heavy viewers y light viewers depende del modo en que se haya obtenido el nivel de exposición a la televisión. Morgan y Shanahan (1996) sugieren obtener una distribución continua y luego dividir la muestra en tres grupos con igual número de integrantes de acuerdo con lo que cada uno de los encuestados haya reportado. El grupo con la menor exposición serán los light viewers, el grupo con mayor exposición serán los heavy viewers y el otro serán los medium viewers. Este procedimiento supone que muestras distintas tendrán distribuciones distintas y, por tanto, los cortes en grupos variarán. Los autores argumentan que no importa tanto el número exacto de horas que se reporten, sino las diferencias entre la mayor o menor exposición al mensaje de la televisión.

El análisis del cultivo organiza las preguntas de sus cuestionarios alrededor de las diferencias entre las características demográficas del mundo de la televisión y las del mundo real.

Por ejemplo, George Gerbner (citado en Morgan y Shanahan, 1996) utiliza el censo general de 1970 de los Estados Unidos según el cual sólo el 1 por ciento de la población masculina trabajadora hacía labores de prevención del crimen o de la aplicación de la ley, mientras que en el mundo de la televisión este segmento de la población representaba el 12 por ciento; en el cuestionario se preguntó el porcentaje que esta pobla- ción representaba y se ofrecían dos alternativas: 1 por ciento o 5 por ciento, que aunque no es exactamente el dato que arroja el análisis de contenido, sí está en la misma línea, es decir, es mucho mayor que la proporción real. Esta última opción, el 5 por ciento, se le llamó «la respuesta de la televisión». El procedimiento para el análisis fue la comparación entre la cantidad de televisión que reporta el entrevistado y si elige la respuesta de la televisión o la del mundo real. En este caso el 59 por ciento de los entrevistados que reportaron ver mayor cantidad de televisión, calificados como heavy viewers, eligieron la respuesta de la televisión, mientras que sólo el 50 por ciento de los que reportaron ver menos televisión, ligth viewers, eligieron la respuesta de la televisión.

Durante 1999 Chory-Assad y Tamborini (2001) realizaron un análisis de contenido en los programas de televisión en los que aparecían médicos para realizar una comparación entre los distintos tipos de programas y las características y valoración de los médicos ahí representados. Encontraron que la imagen de los personajes médicos en general era menos favorable que en un estudio similar de 1995, y que también había diferencias en los atributos del médico dependiendo del tipo de programa.

Después, con base en estos datos realizaron un análisis del cultivo (Chory-Assad y Tamborini 2003) en el que resultó que la exposición de los entrevistados a los distintos tipos de programas funcionaron como predictores de su forma de ver a los médicos de acuerdo con los hallazgos del análisis de contenido. Los televidentes de series de ficción de horario AAA tenían una opinión negativa del carácter ético de los médi- 
cos, su consideración por los demás y su comportamiento, mientras que ver más revistas informativas por televisión estuvo asociado con una buena opinión de la competencia del médico. Con estos resultados se apoya la idea de que la imagen de los médicos del mundo de la televisión se puede relacionar con la imagen que el televidente tiene de los médicos del mundo real, que la televisión de alguna manera contribuye a la construcción de la realidad social que cada televidentelleva a cabo.

\section{Adecuaciones del cultivo: Mainstreaming y resonancia}

A principios de los ochenta se produjo una controversia con los datos que producía el proyecto Indicadores culturales relacionado con el uso de los controles demográficos (edad, sexo, nivel socioeconómico) en sus análisis de cultivo ya que sólo se utilizaban uno a la vez para explorar las relaciones entre la exposición y el cultivo en lugar de utilizarlos simultáneamente. Cuando se intentó el control simultáneo el cultivo se reducía o desaparecía (Morgan y Sanahan, 1996).

Estos resultados condujeron a un refinamiento del análisis, ya que si bien la relación para la muestra completa desaparecía, al revisar las relaciones dentro de los subgrupos, las relaciones entre la exposición y el cultivo formaban patrones particulares para cada subgrupo, es decir, que la exposición a la televisión continuaba acercando las posiciones de los que se exponen más a la televisión independientemente de otras condicionantes (Morgan y Sanahan, 1996).
A este fenómeno le llamaron Mainstreaming, que representa una homogeneización de miradas divergentes y una convergencia de observadores dispersos, en el sentido de que ver la televisión puede absorber o borrar diferencias en perspectivas y comportamientos que derivan de otras influencias sociales, culturales y demográficas (Gerbner, Morgan y Signorielli, 1986). Morgan y Shanahan (1996) sugieren que este proceso debe entenderse como (gravitacional», ya que su fuerza y dirección dependerán de la ubicación del subgrupo analizado con respecto al mainstream, y se determina en el análisis, no necesariamente a priori.

Shrum y Bischak (2001) encontraron poca evidencia de mainstreaming como moderador del efecto de cultivo para el caso específico de riesgo criminal y sugieren que la ocurrencia del fenómeno se limita a los casos en que las creencias de los que ven menos televisión (ligth viewers) de los dos subgrupos evaluados difieren con respecto a determinada variable, que en este caso sería su relación con la experiencia directa del crimen. El caso contrario, cuando existe experiencia directa, análisis del cultivo lo denomina resonancia.

En este mismo estudio, Shrum y Bischak encontraron evidencia para la resonancia, que definen como un refuerzo del mensaje cuando la situación real, el entorno del televidente, es congruente con el mensaje de la televisión. Estos autores sugieren que la violencia televisiva es interpretada en función de la violencia del mundo real, y el televidente ya no puede distinguir una de otra; de acuerdo con sus resultados los estimados de violencia de los heavy viewers fueron significativamente 
mayores que los de los light viewers dentro del grupo con experiencia directa de crimen. El televidente recibe una doble dosis de violencia (Gerbner et al. 1986).

Este tipo de resultados, que resaltan el papel del entorno del televidente y su situación socioeconómica, condujeron también a matizar el papel de la televisión. Treinta años después de los postulados iniciales, en 1996, Morgan y Shanahan acotan el papel de la televisión diciendo que sin ser el único o el decisivo, es un factor que contribuye al mantenimiento de un poder inequitativo.

\section{Cultivo de segundo orden}

En sus inicios el análisis del cultivo se concentraba en cómo los hechos del mundo de la televisión se reflejaban en la percepción de los hechos de la vida real para los televidentes asiduos, preguntando por ocurrencia y concurrencia de acciones (actos de violencia, asesinatos) y actores (personajes masculinos, femeninos, niños, ancianos); las discrepancias entre la conformación de la población en el mundo real y la televisión o los índices de criminalidad (Gerbner y Gross, 1976).

Hacia mediados de los ochenta se conforma el índice de mundo mezquino (mean world index) que sería un segundo nivel de influencia, un cultivo de segundo orden o de sistema de valores (Gerbner, Morgan, Signorielli, 1986). La influencia en la concepción de los hechos del mundo afecta en un nivel cognitivo; el agregado de esas nociones implicarían un cambio de actitud ante el mundo. Si el mundo es un lugar violento en donde ocurren tantos asesinatos, donde hay tantos policías, las posibilidades de que cualquiera sea víctima son altas, y no se puede confiar en la gente; entonces se desarrolla una sensación de aprehensión, desconfianza y alienación, producida por la exposición a la televisión (Gerbner, 1997).

Pero este tipo de análisis de segundo orden no es exclusivo para la violencia, también puede referirse a la actitud hacia los médicos (Chory-Assad y Tamborini, 2003), los fenómenos paranormales (Sparks, Nelson y Campbell. 1997), idealización del matrimonio (Segrin y Nabi, 2002) o el sexismo (Holbert, Shah y Kwank, 2003).

\section{Otros cultivos}

Hasta ahora se ha hecho una breve revisión en líneas generales de la línea principal de los estudios de análisis del cultivo, aquellos que corresponden a lo que Morgan y Shanahan (1996) llaman el grupo cercano a George Gerbner (Michael Morgan, Nancy Signorielli y Larry Gross). Este grupo se ha mantenido concentrado en el análisis del poder manifiesto en los mensajes televisivos a través especialmente de la violencia y su cultivo en los televidentes, cuyos hallazgos principales serían que la televisión, el mundo de la televisión, como arma de los grupos hegemónicos contribuye, junto con otros factores, a la creencia de vivir en un mundo mezquino, sombrío y violento en el que la televisión enseña agresión, desensibilización y un sentido de vulnerabilidad, dependencia y resistencia al cambio (Gerbner 1997).

Sin embargo, el análisis del cultivo también ha concentrado su atención en temas tan diversos como la conciencia ecológica (Shanahan, Morgan, y Stenbjerre. 1997), la 
creencia en fenómenos paranormales (Sparks, Nelson y Campbell, 1997), el mundo laboral (Signorielli y Kahlenberg, 2001), diferencias raciales (Busselle y Crandall, 2002 o la opinión sobre los médicos (Chory-Assad y Tamborini, 2003).

Esta extensión del campo de análisis ha conducido a una controversia en uno de los postulados de origen, el relativo a la homogeneidad del mensaje televisivo. El objetivo original del proyecto Indicadores culturales es qué tipo de conciencia común puede cultivar el sistema total de mensajes ya que sólo el análisis del sistema completo puede revelar el mundo simbólico (Gerbner, 1976).

Dentro de este marco, Shanahan et al.(1997), en un trabajo sobre la preocupación sobre el medio ambiente, dicen que el cultivo no puede atender directamente la relación entre tipos específicos de programas o campañas, pero sí puede averiguar sobre la relación entre la exposición y las creencias medioambientales, lo que enfrenta el problema enun nivel más básico e ideológico; sus resultados de hecho apuntaron en el sentido contrario de lo que predeciría la teoría ya que indicaron que los heavy viewers mostraron una alta preocupación por el medio ambiente. Los autores explican esta discrepancia diciendo que es producto del miedo general que transmite la televisión.

En un trabajo sobre la relación entre las expectativas matrimoniales y el consumo de televisión, Segrin y Nabi (2002) utilizaron dos medidas de exposición, una general y otra exclusiva, para programas asociados con su tema (novelas, comedias románticas). Sus resultados sugieren que el consumo del tipo de programas específico está relacionado positivamente con los constructos que estaban probando relacionados con una visión idealista del ma trimonio, mientras que la medición total de exposición tiene una relación negativa. Las autoras explican esta discrepancia diciendo que el tipo de programas elegido tal vez es distinto al total de la programación, para lo que se apoyan en un trabajo de Signorielli (1991) que sugiere que la programación televisiva transmite una idea del matrimonio como conflictivo, y entonces la relación negativa tiene sentido dentro de la teoría del cultivo.

Las autoras también sugieren que tal vez la explicación radique en que la concepción idealista del matrimonio es la que condiciona el consumo de un tipo específico de programas, en el sentido de usos y gratificaciones ${ }^{3}$

Discrepancias de este tipo también podrían sugerir que la homogeneidad del mensaje televisivo asumida originalmente por el análisis del cultivo, si existe, no es tan fuerte como la homogeneidad entre ciertos tipos específicos de programas. Potter y Chang (1990) encontraron evidencia que apoya esta idea al probar distintas mediciones de exposición y encontrar que la exposición a tipos específicos de programas ofrece un cultivo mayor que la exposición total, y que distintos tipos de programas están relacionados con el cultivo de nociones distintas; por ejemplo, ver novelas está relacionado positivamente con la idea de que las relaciones personales son frágiles mientras que los programas de acción y aventuras están 
relacionados negativamente con ésta. Los autores sugieren que estos hallazgos cuestionan la uniformidad del mensaje televisivo y resaltan la importancia de la selección de contenidos por parte del televidente en relación con la aculturación propuesta por el cultivo.

Chory-Assad y Tamborini $(2001,2003)$ utilizan este argumento para basar su análisis en un tema específico: los médicos y la comparación de distintos tipos de programas que incluyen médicos reales y de ficción y el cultivo de atributos negativos o positivos hacia los médicos del mundo real. Sus resultados también sugieren que la exposición a tipos específicos de programación es un mejor predictor del cultivo de temas relacionados directamente con ellos, que la programación total.

\section{El cultivo internacional}

No sólo en los Estados Unidos se han realizado estudios desde la perspectiva de análisis del cultivo. Gerbner, Gross, Morgan y Signorielli (1996) hacen un recuento de los países en los que se han realizado: Australia, donde se encontró relación entre el consumo de programación estadounidense y la imagen de Australia como un país peligroso; en Inglaterra no se encontró evidencia del cultivo para las imágenes de violencia, aunque el análisis de contenido reveló que la cantidad de violencia en la televisión es menor que en los Estados Unidos; en Holanda se encontraron indicios muy leves de cultivo; en Corea se halló relación entre el consumo de programación estadounidense con actitudes más liberales so- bre género y familia en las mujeres y una actitud hostil hacia los Estados Unidos en estudiantes hombres. También se han realizado estudios en Suecia, Argentina, Tailandia, Taiwán.

En México (Tan, Li y Simpson, 1986) se analizó si la exposición a los programas que los entrevistados consideraban como más representativos de la sociedad estadounidense (Dallas y Dinastía, al aire en esa época) cultivaba imágenes estereotipadas de los estadounidenses. Los resultados relacionan el consumo de estos programas con considerar a los estadounidenses como individualistas, hedonistas, agresivos, crueles y poco honestos.

En un estudio sobre la percepción de violencia de los televidentes de Monterrey, desde la perspectiva del análisis del cultivo, Huerta, Garagarza y Villegas (2000) no encontraron evidencia de cultivo; las diferencias entre los heavy viewers y ligth viewers no fueron significativas.

Los estudios que se realizaron en México y Taiwán (Tan et al. 1986) y en Argentina (Morgan y Shanahan, 1991) no contemplaron un análisis de contenido de la televisión de cada uno de estos países, sino que partieron de la presencia de programas de origen estadounidense para su estudio.

En el caso de Tan et al. (1986) se preguntó directamente la frecuencia con que los entrevistados veían programas estadounidenses que en ese momento eran transmitidos en sus países; en el caso de Argentina se revisó la oferta programática en las guías de televisión disponibles en el área de Bue- 
nos Aires; se analizó la oferta en dos semanas una en 1982 y la otra en 1989. Se consideró la programación como similar a la de los Estados Unidos, especialmente la programación de entretenimiento, las caricaturas, las series y las películas, que ocupaban el 80 por ciento del tiempo de transmisión y, además, eran en su mayoría de origen estadounidense. Otra similitud que Morgan y Shanahan (1991) consideraron importante fue el papel de la publicidad y el carácter comercial de las televisoras.

Gerbner et al. (1996) sugieren que aunque la programación importada desde los Estados Unidos a otros países es alta, no es suficiente para considerar que el fenómeno del cultivo exista; entonces sería importante descubrir cómo se combinan las importaciones con las producciones locales a fin de componer «mundos sintéticos culturalmente específicos».

Los programas norteamericanos importados pueden aumentar, decrecer, o ser irrelevantes dentro de estas dinámicas. Las cuestiones clave son: a) la importancia de la televisión en la cultura y b) la consistencia y coherencia en el sistema total de sus mensajes. Cuanto más importante, consistente y coherente, mayores serán las expectativas de aculturación (Gerbner et al. 1996, p. 59).

En México, el 30 por ciento de la oferta televisiva es de origen estadounidense:

las lecciones de la televisión, por lo menos según su programación, son que toda la realidad que no está en México, se encuentra en Estados Unidos de América (Lozano y Huerta, 2001, p. 208).

\section{DISCUSIÓN Y CONCLUSIONES}

El estudio de Tan et al. (1986), aunque examina desde la perspectiva del cultivo los estereotipos que sobre los estadounidenses cultiva la programación de ese país en los televidentes mexicanos, no revisa el sistema completo de la televisión mexicana y su posible influencia en los televidentes mexicanos.

Los análisis de contenido sobre la televisión siguen encontrando dos grandes discrepancias entre el mundo de la televisión y el mundo real: el mundo de la televisión es más violento que el mundo real (Gerbner y Gross, 1976; Gerbner, 1997; Gerbner et al. 1996) y el mundo de la televisión es un mundo de hombres (Harwood y Anderson, 2002; Signorielli y Kahlenberg, 2001; Elasmar, Hasegawa y Brain, 1999; Vande Berg y Streckfuss, 1992) en el que las mujeres representan una población del 30 por ciento, y desempeñan un papel secundario. Esto específicamente en el contexto de Estados Unidos, aunque podría argumentarse que sería el mismo caso en otros países con sistemas similares al estadounidense que incorporan grandes cantidades de programas de ese origen.

De acuerdo con los resultados de los análisis del cultivo, el sistema de mensajes de la televisión contribuye a la construcción de la realidad de los televidentes (Potter y Chang, 1990), reflejada en estimados que los televidentes asiduos, heavy viewers, declaran de acuerdo con la canti- 
dad de tiempo que se exponen a los contenidos de la televisión.

Estas extensiones del cultivo también condujeron al análisis del cultivo en países distintos a los Estados Unidos, entre ellos México, donde se han realizado muy pocos trabajos bajo este enfoque (Tan et al., 1986; Huerta et al, 2000). Gerbner et al. (1996) sugieren seguir explorando las posibilidades del cultivo en otros países, especialmente en aquellos con altos contenidos estadounidenses en su oferta programática, como es el caso de México.

Morgan y Shanahan (1996) defienden la postura tradicional del cultivo diciendo que para sus fines es suficiente que la relación quede evidenciada, ya que la televisión es un factor, ni el único ni el más importante, de la construcción social que realiza el televidente.

En el sistema televisivo mexicano, compuesto por programación nacional y estadounidense, se advierten diferencias que dependen del origen de los programas, muy especialmente en la presentación de roles masculinos y femeninos (Flores y García, 2004), y por lo tanto el análisis de cultivo debe integrar esta falta de homogeneidad y considerar en el análisis el origen de la programación como un factor de diferencia que condicionará el cultivo.

El cultivo espera relaciones pequeñas entre las variables y asume que la televisión es uno de los elementos que contribuyen a la construcción social que realizan los televidentes, por eso es más importante destacar su presencia que su fuerza (Morgan y Shanahan, 1996). Este trabajo encontró evidencia en ese sentido. Está más allá de los alcances de este trabajo resolver este debate, pero es importante destacarlo y señalar que los datos pueden apoyar ambas posiciones.

En la televisión estadounidense el mundo es un mundo de hombres, y la televisión no contribuye a la equidad, participa del mantenimiento del modelo existente, los hombres reciben las mejores calificaciones y las mujeres son vulnerables, y la televisión, especialmente la estadounidense participa en el mantenimiento de esta situación (Gerbner, 1997).

Aparentemente este trabajo encontró evidencia en este sentido; pero con las diferencias aparentes entre lo que cultivan los sistemas de mensajes televisivos mexicano y estadounidense apunta a identificar las diferencias entre los sistemas. ¿Si cultivan nociones distintas es porque transmiten mensajes distintos? ¿Dónde radica la diferencia?

Casi treinta años después parece haber apoyo en México para lo escrito por Gerbner y Gross (1976): la televisión es la principal arma de la sociedad estadounidense. Es una agencia del orden establecido y como tal sirve en principio para extender y mantener, en lugar de alterar, amenazar o debilitar las concepciones convencionales, las creencias o los comportamientos; no cambiar, resistir el cambio.

Sin embargo, resulta más difícil establecer a qué cambio se resiste una televisión como la mexicana, en la que se enfrentan dos sistemas que parecen diferentes, pero que interactúan entre sí y al mismo tiempo con el televidente. 


\section{NOTAS}

1 Sus actividades han estado bajo los auspicios de la U. S. Surgeon General's Scientific Advisory Committee on Television and Social Behavior, The National Institute of Mental Helth, The White House Office of Telecommunications Policy, las universidades de Pensilvania, Massachussets y Delaware y otras instituciones de los Estados Unidos (Gerbner, Gross, Morgan y Signorielli, 1996).

2 Este enfoque supone que a través de los medios de comunicación masiva se pueden transmitir ciertos estímulos que provocarán respuestas más o menos uniformes en todos los miembros de la audiencia, modelando directamente la opinión pública. Supone una audiencia pasiva y un medio de comunicación con el poder de inocular casi cualquier punto de vista (Lozano, 1996).

3 Usos y gratificaciones sugiere que la audiencia elige exponerse a un medio masivo en particular porque espera que esa exposición satisfaga o llene sus necesidades o intereses sociales o sicológicas (Lozano, 1996).

\section{REFERENCIAS BIBLIOGRÁFICAS}

Busselle, R., Crandall, H. (2002). Television Viewing and perceptions about Race Differences in socioeconomic success. Journal of Broadcasting E Electronic Media, 46,(2). 265.

Chory-Assad, R. M., Tamborini, R. (2003). Television exposure and the public perceptions of physicians. Journal of Broadcasting \& Electronic Media, 47 (2), 197.

Chory-Assad, R. M., Tamborini, R. (2001). Televisión doctors: An Análisis of physicians in fictional and non-fictional televisión programs. Journal of Broadcasting E Electronic Media, 45 (3), 499-521.

Diefenbach, D. L., West, M. D. (2001). Violent crime and poisson regression: A measure and a method for cultivation analysis. Journal of Broadcasting E Electronic Media, 45(3). 432-445.

Elasamar, M., Hasegawa, K., Brain, M. (1999). The portrayal of women in U. S. Prime time television. Journal of Broadcasting E Electronic Media, 43 (1). 20-34.

Fazio, Carlos (2004, 21 de junio) La marcha del 27. La Jornada, p. 21.

Flores, M. L., García, A. (2004) Estereotipos demográficos y étnicos en la televisión mexicana. XVI Encuentro Nacional AMIC.

Gerbner, George (1997). Televisión Violence. The power and the peril. En Humez, J. M., Dines, G., Gender, race and class in the media, 547-557. USA: Sage Publications Inc. 
Gerbner, G.; Morgan, M.; Signorielli, N. (1986). Living with Television: The dyanamics of the Cultivation Process. En J. Bryant, D. Zillmann (compiladores), Perspectives on media efects. Hillsdale, NJ, Lawrence Erlbaum Associates, p. 17-48.

Gerbner, G.; Gross, L; Morgan, M. y Signorielli, N. (1996). Crecer con la televisión: perspectiva de aculturación. En Jennings Bryant, Dolf Zillmann (Comp.) Los efectos de los medios de comunicación. Investigaciones y teorías. Barcelona: Paidós, p. 35- 66.

Harwood, J, Anderson, K (2002). The presence and portrayal of social groups on prime-time television. Communication Reports, 15 (2). 81-97.

Holbert, R. L., Shah, D. V., Kwak, N. (2003). Political Implications of Prime- Time Drama and Sitcom Use: Genres of Representation and Opinion Concerning Women's Rights. Journal of Communication, 53 (1), 45-60.

Huerta, E., Cerda, A. (2002). Qué y cómo se ve la televisión en México: Oferta y consumo en tres áreas metropolitanas. En J. L. Cerda Díaz y F. Aceves González (editores). Anuario de la Comunicación. México: CONEIC IX.

Huerta, E., Garagarza, I., Villegas, R. (2000). Percepción de la violencia en televidentes del área metropolitana de Monterrey, México. IV Encuentro de la Asociación Latinoamericana de Investigadores de la Comunicación. Santiago de Chile.

Larson, M. (1996). Sex Roles and Soap Operas: What Adolescents Learn about Single Motherhood. Sex Roles, 35 1-2. 97-110.

López Islas, J. R, Cerda Cristerna, A. (2001). Violencia en la televisión mexicana: Un análisis del contenido de los treinta programas con mayor nivel de audiencia. Hiper-Textos, 2. Disponible en http://hiper-textos.mty.itesm.mx//num2rafyaida.html

Lozano, J. C. (1996). Teorías e investigación de la comunicación de masas. México: Alhambra.

Lozano, J. C. (2004). Mexican research on the supply and consumption of foreign television contents. Conference of the International Association for Media and Communication Research(IAMCR), Porto Alegre, Brasil.

Lozano, J. C. y Huerta, E. (2001). La programación televisiva mexicana de 1999 desde la perspectiva de la diversidad. En J. L. Cerda Díaz y F. Aceves González (Editores). Anuario de la Comunicación. México: CONEIC VIII.197-221.

Mares, M. (1996). The Role of Source Confusion in Television's Cultivation of Social Reality Judgments. Human Communication Research, 32 (2). 278-297.

Morgan, M y Shanahan, J. (1991). Television and the Cultivation of political attitudes in Argentina. Journal of Communication, 41 (1). 88-103.

Morgan, M. y Shanahan, J. (1996). Two Decades of Cultivation Research: An Appraisal and Meta-Analysis. Communication Yearbook, 20, 1-45. 
Potter, W. J., Chang, I. (1990). Television Exposure Measures and the Cultivation Hipothesis. Journal of Broadcasting E Electronic Media, 34 (3). 313-333.

Potter, J. (1994). Cultivation theory and research: A methodological critique. Journalism Monographs, 174. 1.

Román, J. (2000, julio). Ultimátum a los talk shows. La jornada. Disponible en www: http:// zeus.Infolatina.com.mx/universidad/WReturn.p. Consultada el 5 de julio de 2008.

Segrin, C., Nabi, R. L. (2002). Does Television Viewing Cultivate Unrealistic Expextations About Marriage. Journal of Communication, 52 (2). 247-263.

Signorielli, N. (1991). Adolescents and ambivalence toward marriage: A cultivation analysis. Youth and Society, 23. 121-149.

Signorielli, N; Gerbner, G., Morgan, M. (1995). Violence on Televisión: The Cultural Indicators Project. Journal Of Broadcasting \& Electronic Media, 32 (2). 278.

Signorielli, N., Kahlenberg, S. (2001). Television's world of work inthe nineties. Journal of Broadcasting E Electronic Media, 45(1). 4-22.

Shanahan, J., Morgan, M., Stenbjerre, M. (1997). Green or Brown? Television and the Cultivation of Environmental Concern. Journal of Broadcasting E Electronic Media, 41 (2), 305-323.

Shrum, L. J. (2001). Processing Strategy Moderates the Cultivation Effect. Human Communication Research, 27 (1). 94-120.

Shrum, L., J. (1996). Psycological Processes Underlying Cultivation Effects: Further tests of Construct Accessibility. Human Communication Research, 22 (4), 482-509.

Shrum, L. J. y Darmanin, V. (2001). Mainstreaming, Resonance, and impersonal impact. Testing moderators of the cultivation effect for estimates of crime risk. Human Communication Research, 27 (2). 187-215.

Sparks, G. G., Nelson, C. L. y Campbell R. G. (1997). The relationship Between Exposure to Televised Messages About Paranormal Phenomena and Paranormal Beliefs. Journal of Broadcasting E Electronic Media, 41, 345-359.

Tan, A. S.; Li, S. y Simpson, C. (1986). American TV and Social Stereotypes of Americans in ${ }^{4}$ Taiwan and Mexico. Journalism Quarterly, 63. 809-814.

Vande Berg, L. R. y Streckfuss, D. (1992). Prime-time Television's Portrayal of Women and the World of Work: A demographic profile. Journal of Broadcasting \& Electronic Media, 36 (2). 195-208.

Zhang, Y. B. y Harwood, J. (2002). Television viewing and Perceptions of Tradicional Chines Values among Chines College Students. Journal of Broadcasting E Electronic Media, 46 (2). 245-264. 